\title{
FORMULATION AND EVALUATION OF ATENOLOL AND INDAPAMIDE SR MATRIX TABLET FOR TREATMENT OF HYPERTENSION
}

\author{
Sarika Pundir*, Ashutosh Badola \\ Shri Guru Ram Rai Institute of Technology \& Science P.O. Box - 80, Patel Nagar, \\ Dehradun 248001, Uttarakhand, India
}

\begin{abstract}
In the present study we have formulated $\left(f_{1}\right.$ to $f_{6}$ ) matrix tablets of Atenolol and Indapamide for the management of hypertension. As in simultaneous estimation of these drugs it was found that a confined release can be formulated. In the formulation of SR matrix tablet by using different concentration of delayed release agent DCP and pregelatinised starch as disintegrant we prepared tablets by wet granulation method. For sustained release action HPMC polymers were used for film coating. Preformulation studies were performed prior to compression. The compressed SR matrix tablets were evaluated for weight variation, hardness, friability, drug content, disintegration time and invitro drug release using USP dissolution apparatus type 2 (paddle). It was found that the optimized formulation showed $49.33 \%, 48.90 \%, 48.52 \%, 47.65 \%, 46.84 \%$ and $46.51 \%$ release for Atenolol in 12 hours respectively. However, Indapamide released 49.62\%, 49.39\%, 48.72\%, $48.27 \%, 47.59 \%$ and $47.36 \%$ at the end of $12 \mathrm{hrs}$. The IR spectrum study revealed that there is no disturbance in the principal peaks of pure drugs Atenolol and Indapamide. This confirms the integrity of pure drugs and no incompatibility of them with excipients. The stability studies were carried out for the optimized batch for one months and it showed satisfactory results. The kinetic studies of the formulations revealed that diffusion is the predominant mechanism of drug and release follows Zero order, Super case II transport.
\end{abstract}

Keywords: DCP, starch, HPMC, Atenolol, Indapamide, Zero order, simultaneous estimation.

\section{Introduction}

Combination therapy for treatment of various diseases and disorders require long term therapy such as hypertension and diabetes. Combination therapies have various advantages over monotherapy such as problem of dose dependent side effects minimized ${ }^{[1]}$.

The sustained release matrix drug deliveries are to ensure safety and enhancement of efficacy of drug with improved patient compliance. Thus the use of these dosage forms is increasing in treatment of acute and chronic diseases as they maintain the concentration of drug in plasma above minimum effective concentration and below the minimum toxic level for extended period of time ${ }^{[2]}$. Sustained release tablet allowing a twofold or greater reduction in frequency of administration of a drug in comparison with the frequency required by a conventional dosage form ${ }^{[3]}$.A Tablet is a mixture of API and excipients usually in powder form, pressed or compacted in to solid.

${ }^{*}$ Correspondence to author:

Sarika Pundir

Email: sarikapundir.shalu09@gmail.com 
The excipient usually includes binders, disintegrants, sweeteners or flavours and pigments lubricants, glidents ${ }^{[4]}$.Particles of drug are coated with matrix or entire product is matrix coated which along with its main function of sustained action, avoid exposure of unstable drug to the environment and render it stable ${ }^{[5]}$.

Atenolol (Figure 1), [(4-2 - hydroxy-3 - isopropyl - aminopropoxy) phenylacetamide](Figure 1), is a cardioselective $\beta$-blocker. It is reported to lack intrinsic sympathomimetic activity and membranestabilising properties. It may be used alone or concomitantly with other antihypertensive agents including thiazide-type diuretics, hydralazine, prazosin and $\alpha$-methyldopa ${ }^{[6]}$. Besides being one of the most widely used b-blockers clinically, it has often been used as a reference drug in randomized controlled trials of hypertension ${ }^{[7-10]}$. The elimination half-life of atenolol is 6 to 7 hours and there is no alteration of kinetic profile of drug by chronic administration. Following intravenous administration peak plasma levels are reached within 5 minutes. Declines from peak levels are rapid (5 to 10 fold) during the first 7 hours. Following oral doses of $50 \mathrm{mg}$ or $100 \mathrm{mg}$ both bblocking and anti-hypertensive effects persist for at least 24 hours. The drug accumulates in patients with renal failure and dosage should be adjusted for patients whose creatinine clearance is less than $35 \mathrm{~mL} / \mathrm{min} / 1.73 \mathrm{~m} 2^{[11]}$.

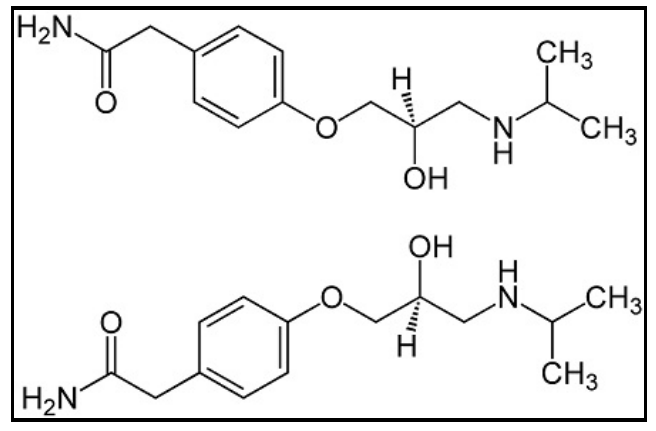

Figure 1: structure of Atenolol

Indapamide (thiazide-type diuretics) is indoline derivatives of chlorosulphonamide (4-Chloro-N-(2methyl-1-indolinyl)-3-sulfamoylbenzamide) (Figure 2). It differs chemically from thiazides and contains only one sulphonamide group and no thiazide ring. Indapamide is an anti-hypertensive diuretic related to the thiazides. The anti-hypertensive effect is associated with an improvement in arterial compliance and a reduction in total and arteriolar peripheral resistance. Indapamide as a first step antihypertensive, has two properties beyond diuresis. First, there is added vasodilation ${ }^{[12]}$. A second unusual property is a high concentration class I and III antiarrhythmic effect ${ }^{[13]}$. Indapamide has a terminal half-life of 14 to 16 hours and effectively lowers the blood pressure over 24 hours. The initial dose is $1.25 \mathrm{mg}$ once daily for 4 weeks, then if needed $2.5 \mathrm{mg}$ daily. Indapamide appears to be more lipid neutral than other thiazides ${ }^{[14]}$ but seems equally likely to cause other metabolic problems such as hypokalemia, hyperglycemia or hyperuricemia. Indapamide ( $2.5 \mathrm{mg}$ daily) does not adversely affect serum triglycerides, LDL cholesterol, the LDLHDL cholesterol ratio, or glucose tolerance.

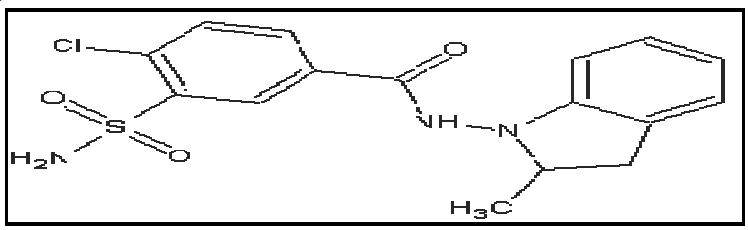

Figure 2: Structure of Indapamide 
Materials and methods

List of material are shown in table 1.

TABLE 1: List of material.

\begin{tabular}{|c|c|}
\hline \multicolumn{2}{|c|}{ List of materials } \\
\hline Atenolol & Sodium starch glycolate \\
\hline Indapamide & Cross carmelose sodium \\
\hline Starch & Aerosil 101 \\
\hline Dibasic calcium phosphate & Magnesium stearate \\
\hline Lactose & Hydroxy propyl methyl cellulose \\
\hline Polyvinyl pyrollidone k-30 & Propyl ethylene glcolate 400 \\
\hline Isopropyl alcohol & \\
\hline
\end{tabular}

Preformulation Studies:

It is one of the important prerequisite in development of any drug delivery system. Preformulations studies were performed on the drug ${ }^{[4]}$ (See table 2).

TABLE 2: List of pre-formulation parameters.

\begin{tabular}{|c|c|}
\hline Pre-formulation parameters of powder & $\begin{array}{c}\text { Evaluation of Pre-formulation parameters of } \\
\text { granules }\end{array}$ \\
\hline Organoleptic characteristics & Bulk Density and Tapped Density \\
\hline Melting Point & Angle of repose \\
\hline Solubility & Hausner's Ratio \\
\hline Compatibility Studies & Compressibility index (Carr's Index) \\
\hline
\end{tabular}

Organoleptic characteristics ${ }^{[4]}$

The colour, odour, and taste of the drug were characterized and recorded. The results are shown in table 3.

TABLE 3: Evaluation of organoleptic properties of powder.

\begin{tabular}{|c|c|c|}
\hline \multirow{2}{*}{ Excipients } & \multicolumn{2}{|c|}{ Description } \\
\cline { 2 - 3 } & Appearance & Odour \\
\hline Atenolol & White to off White crystalline powder & Odourless \\
\hline Indapamide & White powder & Odourless \\
\hline Starch & White to light yellow powder & Odourless \\
\hline Dibasic calcium phosphate & White powder & Odourless \\
\hline Lactose & White crystalline powder & Odourless \\
\hline Polyvinyl pyrollidone k-30 & Creamy white powder & Odourless \\
\hline
\end{tabular}




\begin{tabular}{|c|c|c|}
\hline \multirow{2}{*}{ Excipients } & \multicolumn{2}{|c|}{ Description } \\
\cline { 2 - 3 } & Appearance & Odour \\
\hline Isopropyl alcohol & Colorless & Pleasant \\
\hline Sodium starch glycolate & White powder & Odourless \\
\hline Cross carmelose sodium & White powder & Odourless \\
\hline Aerosil 101 & White powder & Odourless \\
\hline Magnesium stearate & Light white powder & Slight \\
\hline Talc & Light to dark green, brown, white powder & Odourless \\
\hline
\end{tabular}

\section{Determination of Melting Point ${ }^{[4]}$}

Melting point of Atenolol and Indapamide was determined by capillary method. Fine powder of Atenolol and Indapamide was filled in capillary tube (previously sealed at one end). The capillary tube inserted in sample holder of melting point apparatus and a thermometer is also placed in the apparatus. The temperature at which powder melted was noticed (result shown in table 4).

\section{Solubility}

(Result show in table 4)

TABLE 4: Evaluation of pre-formulation parameters of powder

\begin{tabular}{|c|c|c|}
\hline Excipients & Solubility & Melting point \\
\hline Atenolol & $\begin{array}{c}\text { Water }(0.3 \mathrm{mg} / \mathrm{mL}), \text { Ethanol }(3.4 \mathrm{mg} / \mathrm{mL}) \\
\mathrm{DMSO}(18 \mathrm{mg} / \mathrm{mL}) \\
\text { Ether(Practically Insoluble })\end{array}$ & $152-155^{\circ} \mathrm{C}$ \\
\hline Indapamide & $\begin{array}{c}\text { Water(Practically Insoluble })(75 \mathrm{mg} / \mathrm{L}) \\
\text { Alcohol(soluble) } \\
\text { ethyl acetate(soluble) } \\
\text { Acetonitrile(soluble) }\end{array}$ & $161^{\circ} \mathrm{C}$ \\
\hline
\end{tabular}

\section{Compatibility Studies (Drug-Excipients compatibility studies)}

The pure drugs (Atenolol and Indapamide) along with formulation excipients and studies were carried out by mixing definite proportions of drug and excipients(ratio 1:1) and kept on glass vials which are stored at $40^{\circ} \mathrm{C} \pm 2^{\circ} \mathrm{C} \& 75 \pm 5 \% \mathrm{RH}$ for one month ${ }^{[4,19]}$ (result shown in table 5 ).

TABLE 5: Drug-excipients compatibility studies

\begin{tabular}{|c|c|c|}
\hline \multirow{2}{*}{ Excipients } & \multicolumn{2}{|c|}{ Description } \\
\cline { 2 - 3 } & $\begin{array}{c}\text { Starting of study } \\
\text { (Initial) }\end{array}$ & $\begin{array}{c}\text { After one month } \\
\text { (final) }\end{array}$ \\
\hline $\begin{array}{c}\text { Active pharmaceutical } \\
\text { ingredients(Atenolol + Indapamide) }\end{array}$ & White crystalline powder & White crystalline powder \\
\hline API +Starch & White crystalline powder & White crystalline powder \\
\hline API + Dibasic calcium phosphate & White crystalline powder & White crystalline powder \\
\hline API + Lactose & White crystalline powder & White crystalline powder \\
\hline API + Polyvinyl pyrollidone k-30 & White crystalline powder & White crystalline powder \\
\hline
\end{tabular}




\begin{tabular}{|c|c|c|}
\hline \multirow{2}{*}{ Excipients } & \multicolumn{2}{|c|}{ Description } \\
\cline { 2 - 3 } & $\begin{array}{c}\text { Starting of study } \\
\text { (Initial) }\end{array}$ & $\begin{array}{c}\text { After one month } \\
\text { (final) }\end{array}$ \\
\hline API + Sodium starch glycolate & White crystalline powder & White crystalline powder \\
\hline API + Cross carmelose sodium & White crystalline powder & White crystalline powder \\
\hline API + Aerosil 101 & White crystalline powder & White crystalline powder \\
\hline API + Magnesium stearate & White crystalline powder & White crystalline powder \\
\hline API + Talc & White crystalline powder & White crystalline powder \\
\hline
\end{tabular}

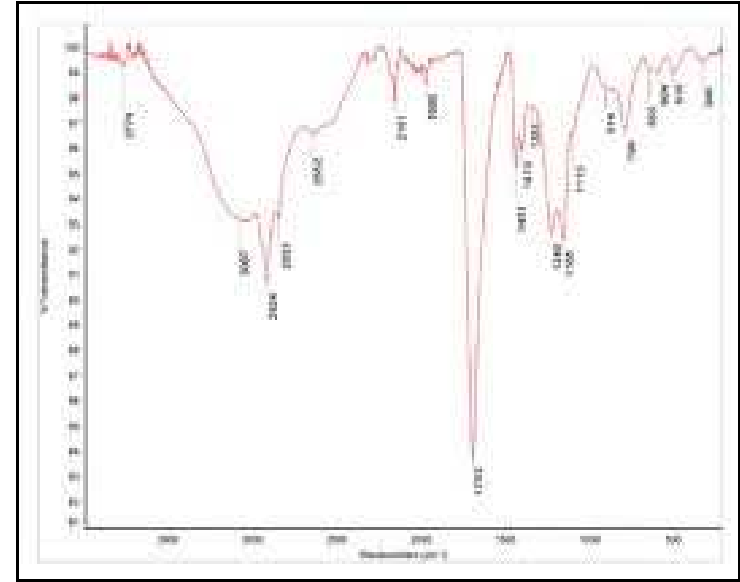

Figure 3: FTIR of Atenolol with excipients.

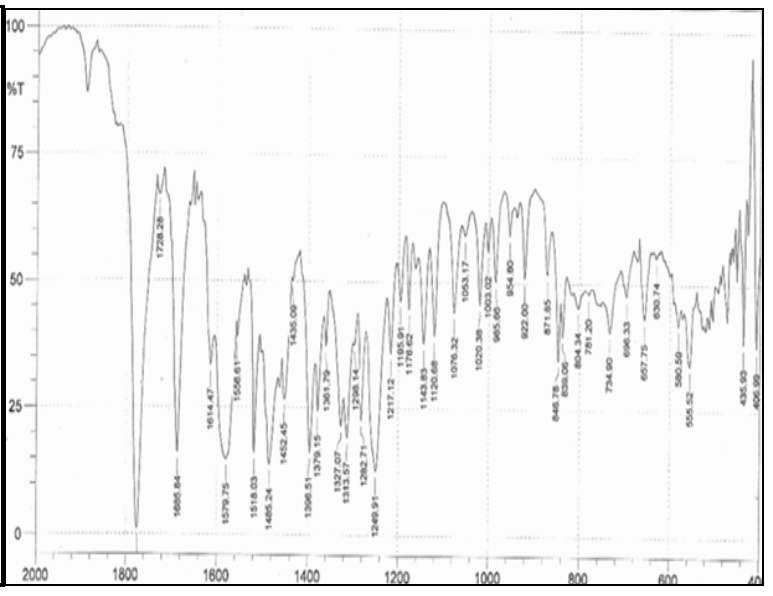

Figure 4: FTIR of Indapamide with excipients.

\section{Evaluation of Pre-formulation parameters of granules ${ }^{[4,17,18]}$}

\section{Determination of Bulk Density and Tapped Density}

$20 \mathrm{~g}$ of the mix blend (W) was introduced into a $100 \mathrm{ml}$ measuring cylinder, and the initial volume was observed. The cylinder was allowed to fall under its own weight on to a hard surface from the height of $2.5 \mathrm{~cm}$ at $2 \mathrm{Sec}$ intervals. The tapping was continued until no further change in volume was noted (result shown in table 9). The bulk density, and tapped density was calculated using the following formulae.

$$
\begin{aligned}
& >\text { Bulk density }=\mathrm{W} / \mathrm{VO}_{O} \\
& >\text { Tapped density }=\mathrm{W} / \mathrm{V}_{\mathrm{F}}
\end{aligned}
$$

Where,

$$
\begin{aligned}
& W=\text { weight of the granules, } \\
& V O=\text { initial volume of the granules. } \\
& V F=\text { final volume of the granules. }
\end{aligned}
$$

\section{Angle of repose}

The angle of repose of powder blend was determined by the funnel method. The accurately weight powder blend were taken in the funnel. The height of the funnel was adjusted in such a way that the tip of the funnel just touched the apex of the powder blend. The powder blend was allowed to flow through the funnel freely on to the surface. The diameter of the powder cone was measured and angle of repose was calculated using the following equation(shown limits in table $6)$.

$$
\theta=\tan ^{-1} h / r
$$


Where, $h$ and $r$ are the height and radius of the powder cone respectively (result show in table 9).

TABLE 6: Angle of repose

\begin{tabular}{|l|c|c|}
\hline SL. & Angle of repose( $\boldsymbol{\theta})$ & Type of flow \\
\hline 1 & $<25$ & Excellent \\
\hline 2 & $25-30$ & Good \\
\hline 3 & $30-40$ & Passable \\
\hline 4 & $>40$ & Very poor \\
\hline
\end{tabular}

\section{Hausner's Ratio}

It indicates the flow properties of the granules and is measured by the ratio of tapped density to the bulk density (shown limits in table 7)(result shown in Table 9)

Hausner's Ratio = Tapped density/Bulk density

TABLE 7: Hausner's ratio

\begin{tabular}{|c|c|c|}
\hline Sr. No. & Hausner's Ratio & Property \\
\hline 1. & $0-1.2$ & Free flowing \\
\hline 2. & $1.2-1.6$ & Cohesive powder \\
\hline
\end{tabular}

\section{Compressibility index (Carr's Index)}

Compressibility index is an important measure that can be obtained from the bulk and tapped densities. In theory, the less compressible a material the more flowable it is (limits shown in table 8).

TABLE 8: Carr's index

\begin{tabular}{|c|c|}
\hline Carr's Index & Properties \\
\hline $5-12$ & Free flowing \\
\hline $12-16$ & Good \\
\hline $18-21$ & Fair \\
\hline $23-35$ & Poor \\
\hline $33-38$ & Very poor \\
\hline$>40$ & Extremely poor \\
\hline
\end{tabular}

A material having values of less than $20 \%$ has good flow property (result shown in table 9 ).

$$
\mathrm{Cl}=\frac{\text { Tapped density-Bulk density }}{\text { Tapped density }} \times 100
$$

TABLE 9: Evaluation of pre-formulation parameters of granules

\begin{tabular}{|c|c|c|c|c|c|}
\hline $\begin{array}{c}\text { Formula } \\
\text {-ion }\end{array}$ & Bulk density & Tapped density & Carr's index & Hausner's ratio & $\begin{array}{c}\text { Angle of } \\
\text { repose }\end{array}$ \\
\hline F1 & 0.486 & 0.567 & 14.28 & 1.16 & 21.30 \\
\hline F2 & 0.479 & 0.561 & 14.61 & 1.17 & 20.80 \\
\hline F3 & 0.487 & 0.558 & 12.72 & 1.14 & 21.80 \\
\hline
\end{tabular}




\begin{tabular}{|c|c|c|c|c|c|}
\hline $\begin{array}{c}\text { Formula } \\
\text {-ion }\end{array}$ & Bulk density & Tapped density & Carr's index & Hausner's ratio & $\begin{array}{c}\text { Angle of } \\
\text { repose }\end{array}$ \\
\hline F4 & 0.478 & 0.563 & 15.09 & 1.15 & 24.22 \\
\hline F5 & 0.476 & 0.559 & 14.84 & 1.17 & 22.78 \\
\hline F6 & 0.482 & 0.570 & 15.43 & 1.18 & 22.29 \\
\hline
\end{tabular}

\section{Preparation of Standard Calibration Curve of Atenolol}

ATL $50 \mathrm{mg}$ was accurately weighed and dissolved in $50 \mathrm{ml}$ methanol. From the above solutions 1 $\mathrm{ml}$ was diluted to $10 \mathrm{ml}$ with methanol to produce $100 \mu \mathrm{g} / \mathrm{ml}$ of ATL. Suitable aliquot of this stock solution of ATL was diluted with methanol to obtain $6-30 \mu \mathrm{g} / \mathrm{ml}$ of ATL. Absorbance of the above dilution was determined at $225 \mathrm{~nm}$ absorbance (result shown in table 10). Calibration curve was plotted as concentration Vs absorbance. (Figure 5)

TABLE 10: Standard calibration curve of atenolol and indapamide

\begin{tabular}{|c|c|c|c|}
\hline \multicolumn{2}{|c|}{ Atenolol } & \multicolumn{2}{c|}{ Indapamide } \\
\hline Concentration & Absorbance & Concentration & Absorbance \\
\hline 0 & 0 & 0 & 0 \\
\hline 6 & 0.2038 & 2 & 0.3158 \\
\hline 12 & 0.4044 & 4 & 0.6356 \\
\hline 18 & 0.6034 & 6 & 0.9716 \\
\hline 24 & 0.8046 & 8 & 1.2830 \\
\hline 30 & 0.9940 & 10 & 1.5868 \\
\hline
\end{tabular}

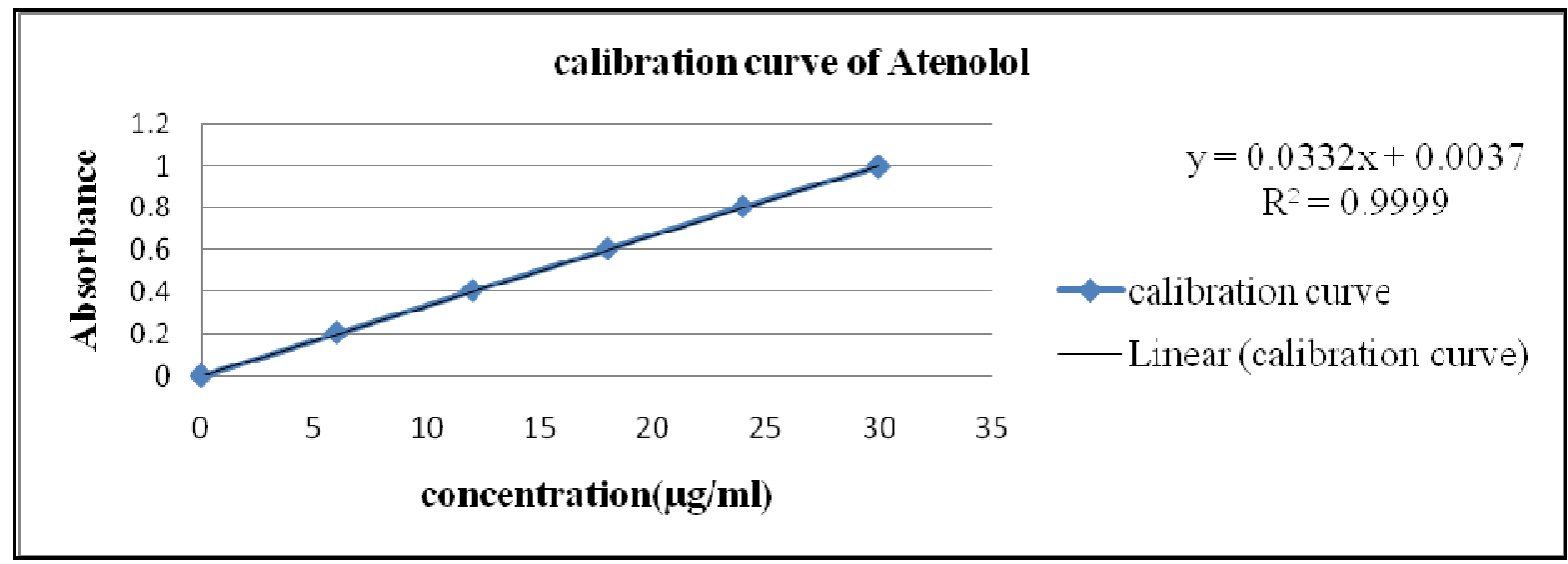

Figure 5: Calibration curve of Atenolol

\section{Preparation of Standard Calibration Curve of Indapamide}

IND $50 \mathrm{mg}$ was accurately weighed and dissolved in $50 \mathrm{ml}$ methanol. From the above solutions 1 $\mathrm{ml}$ was diluted to $10 \mathrm{ml}$ with methanol to produce $100 \mu \mathrm{g} / \mathrm{ml}$ of IND. Suitable aliquot of this stock solution of IND was diluted with methanol to obtain $0-10 \mu \mathrm{g} / \mathrm{ml}$ IND separately. Absorbance of the above dilution was determined at $240 \mathrm{~nm}$ absorbance (result shown in table 10). Calibration curve was plotted as concentration Vs absorbance. (Figure 6) 


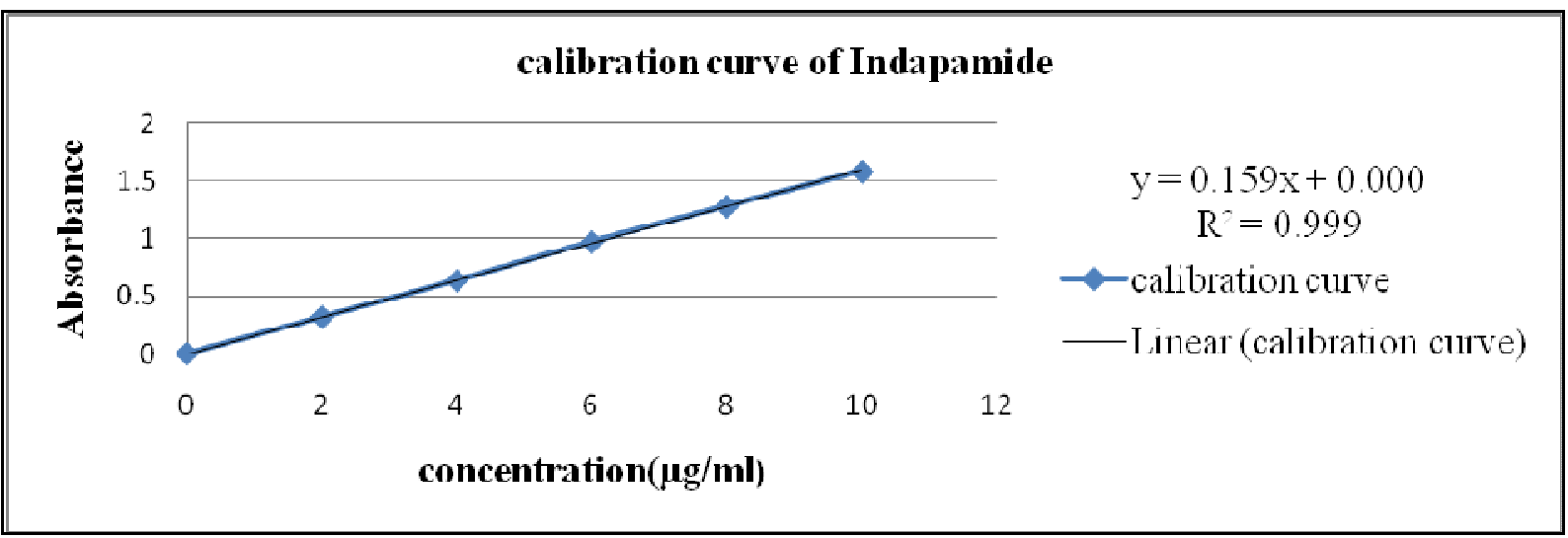

Figure 6: Calibration curve of Indapamide

\section{Preparation of SR matrix tablets}

Sustained release matrix tablet of Atenolol and Indapamide was manufactured by wet granulation technique. Atenolol, Indapamide and lactose for each batch was pre-blended for 5 minutes. Add DCP, starch and blended for additional 5 minutes in RMG. Finally paste (transparent homogenous solution) of pvp k-30 and IPA was added for binding and the formulation was mixed for further minutes to achieve an agglomerated mass. The granules were air dried for $5 \mathrm{~min}$ and then dried in FBD till moisture content achieved 1-2\%. The dried granules were passed through the sieve (sieve no. 30\#). Dried granules were lubricated with SSG, CCS, aerosil 101, magnesium sterate and talc for 5 minutes. Tablets were manufactured using a tablet compression machine and then compressed tablets were coated (sustained release film coating). (Table 11)

TABLE 11: Formulation chart

\begin{tabular}{|c|c|c|c|c|c|c|}
\hline \multirow{2}{*}{ Ingredients } & \multicolumn{6}{|c|}{ Formulation code } \\
\hline & $\mathrm{F} 1$ & F2 & F3 & $\mathrm{F} 4$ & $\mathrm{~F} 5$ & F6 \\
\hline Atenolol(mg) & 50 & 50 & 50 & 50 & 50 & 50 \\
\hline Indapamide(mg) & 2.5 & 2.5 & 2.5 & 2.5 & 2.5 & 2.5 \\
\hline Starch $(\mathrm{mg})$ & 70 & 75 & 80 & 85 & 90 & 95 \\
\hline $\begin{array}{l}\text { Dibasic calcium } \\
\text { phosphate }(\mathrm{mg})\end{array}$ & 30 & 27.5 & 25 & 22.5 & 20 & 17.5 \\
\hline Lactose(mg) & 20 & 17.5 & 15 & 12.5 & 10 & 7.5 \\
\hline $\begin{array}{c}\text { Polyvinyl pyrollidone k- } \\
30(\mathrm{mg})\end{array}$ & 3 & 3 & 3 & 3 & 3 & 3 \\
\hline Isopropyl alcohol(ml) & 0.02 & 0.02 & 0.02 & 0.02 & 0.02 & 0.02 \\
\hline $\begin{array}{l}\text { Sodium starch } \\
\text { glycolate }(\mathrm{mg})\end{array}$ & 5 & 5 & 5 & 5 & 5 & 5 \\
\hline $\begin{array}{l}\text { Cross carmelose } \\
\text { sodium }(\mathrm{mg})\end{array}$ & 5 & 5 & 5 & 5 & 5 & 5 \\
\hline Aerosil 101(mg) & 4.5 & 4.5 & 4.5 & 4.5 & 4.5 & 4.5 \\
\hline
\end{tabular}




\begin{tabular}{|c|c|c|c|c|c|c|}
\hline \multirow{2}{*}{ Ingredients } & \multicolumn{6}{|c|}{ Formulation code } \\
\cline { 2 - 7 } & F1 & F2 & F3 & F4 & F5 & F6 \\
\hline Magnesium stearate(mg) & 5 & 5 & 5 & 5 & 5 & 5 \\
\hline Talc(mg) & 5 & 5 & 5 & 5 & 5 & 5 \\
\hline Total weight & 200.02 & 200.02 & 200.02 & 200.02 & 200.02 & 200.02 \\
\hline
\end{tabular}

\section{Analysis of laboratory mixture}

Accurately weighed $50 \mathrm{mg}$ of ATL and $2.5 \mathrm{mg}$ of IND were transferred to $100 \mathrm{ml}$ volumetric flask, dissolved in methanol and volume was adjusted up to the mark with same solvent. Appropriate aliquot $0.5 \mathrm{ml}$ was transferred to $10 \mathrm{ml}$ volumetric flask and volume was adjusted up to the mark with same solvent to obtained concentration $30 \mu \mathrm{g} / \mathrm{ml}$ of ATL and $1.5 \mu \mathrm{g} / \mathrm{ml}$ of IND. The absorbances of solutions were recorded at $225.0 \mathrm{~nm}$ and $240.0 \mathrm{~nm}$ against blank. Concentration of each drug was obtained by solving the simultaneous equation.

$\mathrm{C} 1=(\mathrm{A} 2 \mathrm{ay} 1-\mathrm{A} 1 \mathrm{ay} 2) /($ ax2ay1 - ax1ay2)

$\mathrm{C} 2=(\mathrm{A} 1 \mathrm{ax} 2-\mathrm{A} 2 \mathrm{ax} 1) /(\mathrm{ax} 2 \mathrm{ay} 1-\mathrm{ax} 1 \mathrm{ay} 2)$

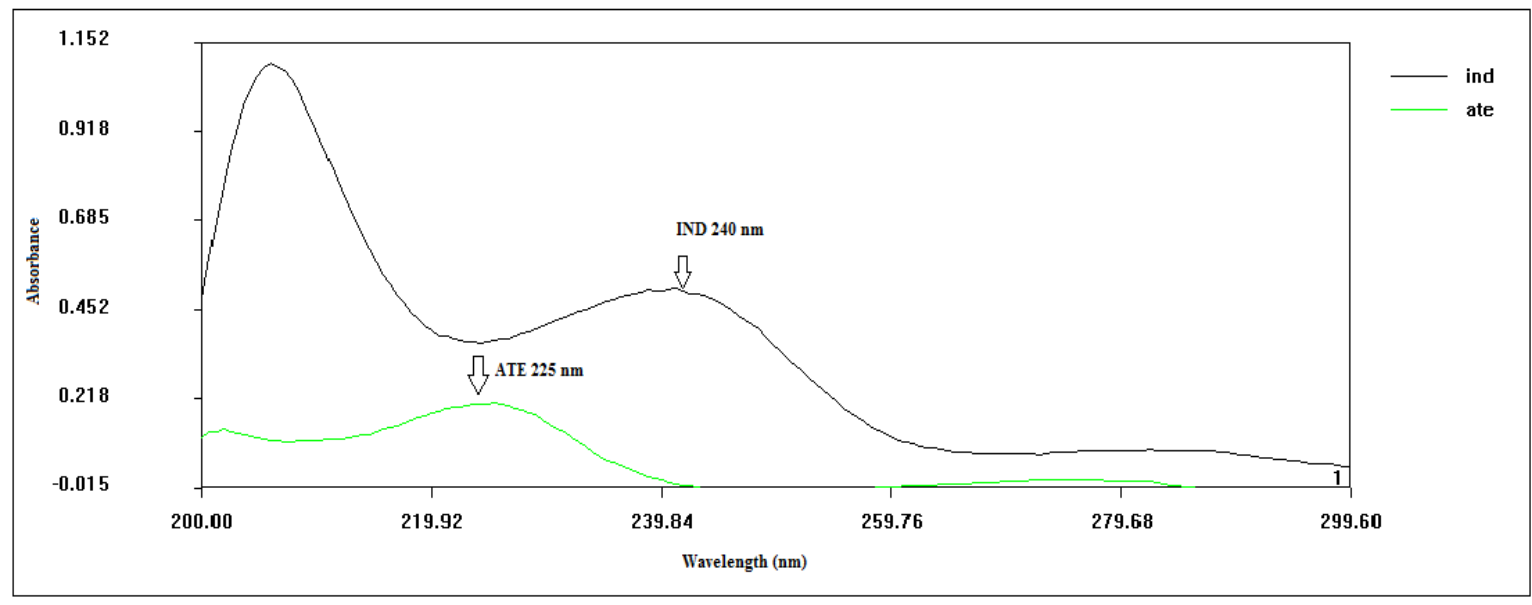

Figure 7: Simultaneous estimation of Atenolol and Indapamide SR matrix tablet

\section{Evaluation parameter ${ }^{[4,15]}$}

\section{General Appearance}

The general appearance of a tablet, its identity and general elegance is essential for consumer acceptance, for control of lot-to-lot uniformity and tablet-to-tablet uniformity. The control of general appearance involves the measurement of size, shape, color, presence or absence of odor, taste etc ${ }^{[4]}$.( result shown in table 12 )

\section{Size \& Shape}

It can be dimensionally described \& controlled. The thickness of a tablet is only variables. Tablet thickness can be measured by micrometer or by other device. Tablet thickness should be controlled within $\mathrm{a} \pm 5 \%$ variation of standard value. 


\section{Organoleptic properties}

Colour distribution must be uniform with no mottling. For visual colour comparison compare the colour of sample against standard colour.

\section{Weight variation}

All prepared matrix tablets were evaluated for weight variation as per USP XXIV monograph. Twenty tablets of each batch were used to evaluate weight variation among tablets and standard deviation was calculated ${ }^{[4,15]}$. (Result shown in table 12)

\section{Friability}

20 tablets were taken randomly and placed on a sieve. Loose dust was removed with the aid of a soft brush. Tablet samples were weighed accurately and placed in Roche friabilator. After the given number of rotations ( 100 rotations) loose dust was removed from the tablets as before and the finally tablets weight determined. The lost in weight indicate the ability of the tablets to withstand stress of handling and transportation ${ }^{[4,15]}$. (Result shown in table 12)The percentage friability was determined by using following formula:

\section{$\%$ friability = initial weight- final weight/initial weight $\times 100$}

\section{Hardness}

The hardness of the tablets was determined by diametric compression using a Hardness testing apparatus (Monsanto tester). A tablet hardness of about $4-5 \mathrm{~kg}$ is considered adequate for mechanical stability. Determinations were made in triplicate [4, 15]. (Result shown in table 11)

\section{Thickness}

20 tablets were taken randomly for this purpose, the tablet thickness were determined individually with the aid of a vernier calliper ${ }^{[4,15]}$. (Result shown in table 12)

\section{Uniformity of content of active ingredient}

\section{Content uniformity}

In this test, 30 tablet are randomly selected for the sample and at least 10 of them are assayed individually. Nine of the 10 tablet must contain not less than $85 \%$ and more than $115 \%$ of the label drug content. The 10 tablet may not less than $75 \%$ or more than $125 \%$ of the labelled content. If these condition not met. The tablet remaining from the 30 must be assayed individually, and none may fall outside of the $85 \%$ to $115 \%$ range. In evaluating a particular lot of tablet, several sample of tablet should be taken from various part of production run to satisfy statistical procedure ${ }^{[4,15]}$. (Result shown in table 12)

\section{Disintegration test}

Sustained released matrix tablets are not expected to disintegrate like convectional tablets. Disintegration time was measured by using 6 tablets from each formulation, i.e. one tablet per disintegrating basket. Disintegration Apparatus was name of apparatus ${ }^{[4,15]}$.

TABLE 12: Post compression parameters.

\begin{tabular}{|c|c|c|c|c|c|}
\hline Formulation & $\begin{array}{c}\text { Weight } \\
\text { variation }\end{array}$ & $\begin{array}{c}\text { Hardness } \\
\left(\mathbf{k g} / \mathbf{c m}^{\mathbf{2}}\right)\end{array}$ & $\begin{array}{c}\text { Friability } \\
(\%)\end{array}$ & $\begin{array}{c}\text { Thicknes } \\
\mathbf{s} \\
(\mathbf{m m})\end{array}$ & $\begin{array}{c}\text { Content uniformity } \\
(\%)\end{array}$ \\
\hline F1 & 200 & 5.7 & 0.41 & 3.83 & 99.8 \\
\hline
\end{tabular}




\begin{tabular}{|c|c|c|c|c|c|}
\hline Formulation & $\begin{array}{c}\text { Weight } \\
\text { variation }\end{array}$ & $\begin{array}{c}\text { Hardness } \\
\left(\mathbf{k g} / \mathbf{c m}^{\mathbf{2}} \mathbf{)}\right.\end{array}$ & $\begin{array}{c}\text { Friability } \\
\mathbf{( \% )}\end{array}$ & $\begin{array}{c}\text { Thicknes } \\
\mathbf{s} \\
\mathbf{( m m})\end{array}$ & $\begin{array}{c}\text { Content uniformity } \\
\mathbf{( \% )}\end{array}$ \\
\hline F2 & 200 & 5.5 & 0.62 & 3.85 & 99.5 \\
\hline F3 & 201 & 6.0 & 0.37 & 3.69 & 99.7 \\
\hline F4 & 200 & 6.0 & 0.29 & 3.67 & 99.9 \\
\hline F5 & 201 & 6.0 & 0.37 & 3.69 & 99.8 \\
\hline F6 & 200 & 5.9 & 0.41 & 3.85 & 99.6 \\
\hline
\end{tabular}

\section{Dissolution test (In-vitro dissolution study)}

The release rate of Atenolol and Indapamide SR matrix tablet was determined using United State Pharmacopoeia (USP) XXIV dissolution testing apparatus II (paddle method). The in vitro release study was performed in $0.1 \mathrm{~N} \mathrm{HCL} \mathrm{pH} 1.2$ for $2 \mathrm{hrs}$ and in phosphate buffer $\mathrm{pH} 6.8$ up to $12 \mathrm{hrs}$. At every interval $10 \mathrm{ml}$ of the solution was withdrawn from the dissolution apparatus at 1, 2, 3, 4, 5, 6, $7,8,9,10,11$ and 12 hours and samples were replaced with fresh dissolution medium to maintain the constant volume. The samples were filtered through a filter and absorbance of these solutions was measured at $225.0 \mathrm{~nm}$ (Atenolol) and $240.0 \mathrm{~nm}$ (Indapamide) using Elico SL $210 \mathrm{UV} / \mathrm{V}$ is double beam spectrophotometer ${ }^{[4,15]}$. (Result shown in table 13,14)

TABLE 13: In-vitro drug release of atenolol

\begin{tabular}{|c|c|c|c|c|c|c|}
\hline \multirow{2}{*}{ Time(hrs) } & \multicolumn{7}{|c|}{ Cumulative \% drug release } \\
\cline { 2 - 7 } & \multicolumn{7}{|c|}{ Formulation } \\
\cline { 2 - 7 } & $\mathbf{F 1}$ & F2 & F3 & F4 & F5 & F6 \\
\hline $\mathbf{0}$ & 0 & 0 & 0 & 0 & 0 & 0 \\
\hline $\mathbf{1}$ & 5.04 & 4.87 & 4.77 & 4.44 & 4.06 & 3.95 \\
\hline $\mathbf{2}$ & 8.83 & 8.62 & 8.29 & 8.15 & 7.96 & 7.31 \\
\hline $\mathbf{3}$ & 13.17 & 12.68 & 12.3 & 12.03 & 11.76 & 11.6 \\
\hline $\mathbf{4}$ & 17.34 & 16.8 & 16.15 & 15.93 & 15.72 & 15.34 \\
\hline $\mathbf{5}$ & 21.25 & 21.03 & 20.49 & 20.22 & 19.62 & 19.24 \\
\hline $\mathbf{6}$ & 25.75 & 24.61 & 24.34 & 24.01 & 23.58 & 23.2 \\
\hline $\mathbf{7}$ & 29.33 & 28.51 & 28.03 & 27.75 & 27.32 & 27.16 \\
\hline $\mathbf{8}$ & 33.39 & 33.07 & 32.42 & 31.98 & 31.55 & 31.17 \\
\hline $\mathbf{9}$ & 37.51 & 37.19 & 36.97 & 36.48 & 35.78 & 35.62 \\
\hline $\mathbf{1 0}$ & 41.8 & 41.31 & 40.93 & 40.5 & 39.68 & 38.81 \\
\hline $\mathbf{1 1}$ & 45.16 & 44.72 & 44.45 & 44.02 & 43.42 & 43.04 \\
\hline $\mathbf{1 2}$ & 49.33 & 48.9 & 48.52 & 47.65 & 46.84 & 46.51 \\
\hline
\end{tabular}

TABLE 14: In-vitro drug release of indapamide

\begin{tabular}{|c|c|c|c|c|c|c|}
\hline Time(hrs) & \multicolumn{7}{|c|}{ Cumulative \% drug release } \\
\cline { 2 - 7 } & \multicolumn{7}{|c|}{ Formulation } \\
\cline { 2 - 7 } & F1 & F2 & F3 & F4 & F5 & F6 \\
\hline 0 & 0 & 0 & 0 & 0 & 0 & 0 \\
\hline 1 & 5.18 & 4.73 & 4.28 & 3.83 & 3.6 & 3.38 \\
\hline 2 & 9.69 & 9.24 & 8.79 & 8.34 & 7.89 & 7.66 \\
\hline
\end{tabular}




\begin{tabular}{|c|c|c|c|c|c|c|}
\hline \multirow{2}{*}{ Time(hrs) } & \multicolumn{7}{|c|}{ Cumulative \% drug release } \\
\cline { 2 - 7 } & \multicolumn{7}{|c|}{ Formulation } \\
\hline 3 & 13.53 & 13.3 & 12.85 & 12.63 & 12.18 & 11.72 \\
\hline 4 & 17.14 & 16.69 & 16.24 & 16.01 & 15.78 & 15.33 \\
\hline 5 & 20.97 & 20.52 & 20.3 & 19.84 & 19.62 & 18.94 \\
\hline 6 & 25.26 & 25.03 & 24.58 & 24.36 & 23.9 & 23.00 \\
\hline 7 & 29.54 & 29.09 & 28.64 & 28.42 & 27.96 & 27.51 \\
\hline 8 & 33.6 & 33.38 & 32.93 & 32.25 & 31.8 & 31.12 \\
\hline 9 & 37.66 & 37.21 & 36.99 & 36.54 & 35.86 & 35.41 \\
\hline 10 & 41.27 & 40.82 & 40.37 & 40.15 & 39.69 & 39.47 \\
\hline 11 & 46.01 & 45.56 & 44.88 & 44.43 & 43.98 & 43.53 \\
\hline 12 & 49.62 & 49.39 & 48.72 & 48.27 & 47.59 & 47.36 \\
\hline
\end{tabular}

Drug release kinetics ${ }^{[5,19,20]}$

Zero-order kinetics ${ }^{[19]}$

Drug dissolution from pharmaceutical dosage forms that do not disaggregate and release the drug slowly can be represented by the following equation:

$A_{0}+k_{0} t=A_{t}$,

where $A_{0}$ is the initial amount of drug in the solution, $A_{0}$ is the amount of drug in the solution at time $t$ and $k_{0}$ is the zero order release constant.

First-order kinetics ${ }^{[19]}$

To study the first order release rate kinetics, the release rate data were fitted to the following equation.

$\mathrm{Inc}=\operatorname{lnc}_{0}-\mathrm{kt}$,

after converting to logarithms yields,

$\log \mathrm{c}=\log \mathrm{c}_{0}-\mathrm{kt} / 2.303$

where $\mathrm{c}$ represents the fraction of drug released in time $\mathrm{t}$ and $\mathrm{kt}$ is the first-order release constant.

\section{Higuchi's model ${ }^{[20]}$}

Higuchi developed a theortical model for studying the release of water-soluble and poorly soluble drugs from a variety of matrices, including semisolid and solids.

$$
\mathrm{Q}_{\mathrm{t}}=\mathrm{K}_{\mathrm{H}} \mathrm{t}^{1 / 2}
$$

where $Q_{t}$ represents the fraction of drug released in time $t$ and $K_{H}$ is the Higuchi dissolution constant.

\section{Korsmeyer-Peppas model ${ }^{[5]}$}

In order to understand the mode of release of drugs from polymer matrices, the data were fitted to the following power low equation.

$\mathrm{Mt} / \mathrm{M}=\mathrm{Kt}^{\mathrm{n}}$,

where $M t$ is the drug released at time $t, M$ is the amount of drug released at infinite time, $K$ is a kinetic constant, and $\mathrm{n}$ is the diffusion exponent related to the mechanism of the release.(Table 15). 
TABLE 15: N- value limits for in-vitro drug release

\begin{tabular}{|c|c|c|c|}
\hline \multicolumn{3}{|c|}{ Release exponent(n) } & \multirow{2}{*}{ Drug transport mechanism } \\
\hline Slab & Cylinder & sphere & Fickian diffusion \\
\hline 0.5 & 0.45 & 0.43 & Anomalous transport (non Fickian) \\
\hline $0.5<\mathrm{n}>1.0$ & $0.45<\mathrm{n}>0.85$ & $0.43<\mathrm{n}>0.85$ & Case-II transport \\
\hline 1.0 & 0.85 & 0.85 & Super case-II transport \\
\hline$>1.0$ & $>>1.0$ & $>1.0$ & \\
\hline
\end{tabular}

\section{Results and Discussion}

The Prepared SR matrix tablets of Atenolol and Indapamide met the standard Pharmacopoeial requirements. In the present study Atenolol and Indapamide SR matrix tablets were prepared by wet granulation process by using ingredients shown in (table 1 and table 11). A total number of six formulations were prepared. The values of Preformulation parameters evaluated were within prescribed limit and indicated good fine flow property (table 3, 4, 5 and 6). The data of evaluated tablets such as weight variation, hardness, thickness, friability, content uniformity and In-vitro disintegration time are shown in (table 12). All the formulation showed very low drug release in 0.1 $\mathrm{N} \mathrm{HCL}(\mathrm{pH} 1.2)$ and complete drug release showed in phosphate buffer at $\mathrm{pH} 6.8$. Thus it can be concluded that when $\mathrm{pH}$ rises above $\mathrm{pKa}$, rapid increase in solubility occurs. The release of Atenolol and Indapamide from tablets was slow and sustained over longer period of time. The result of dissolution studies of formulations are shown in table 13, 14 and figures 8 to 13 .

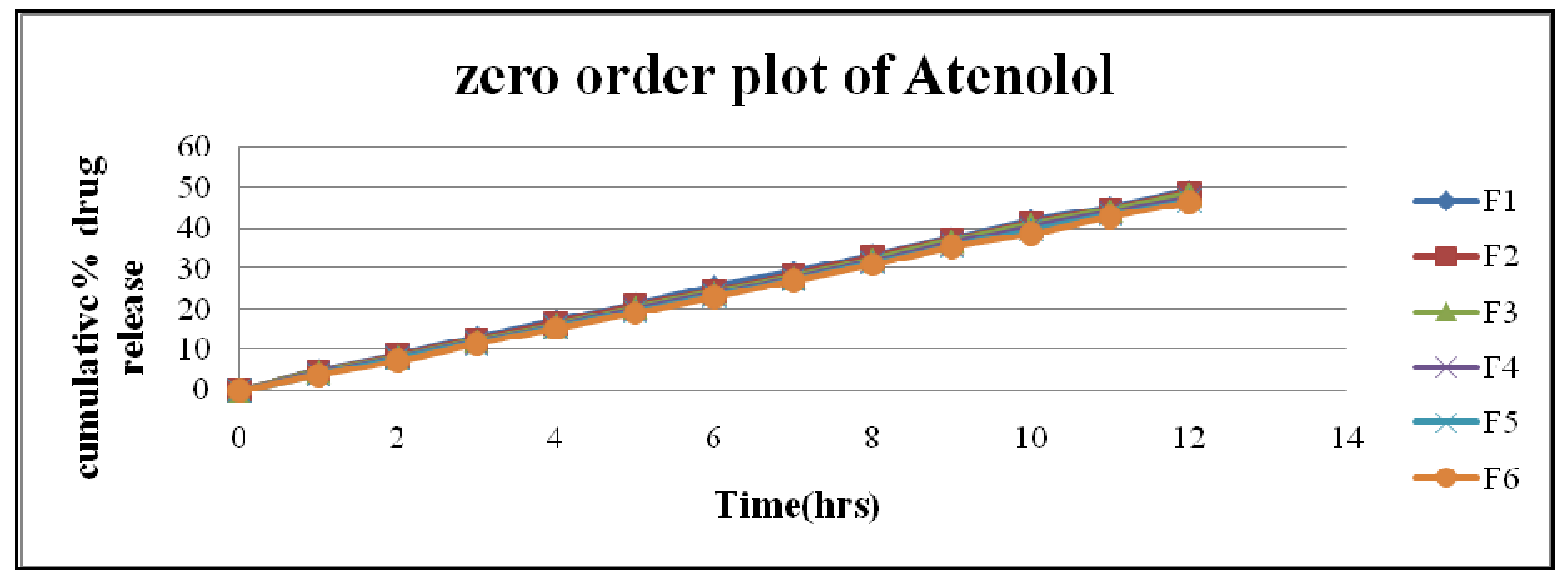

Figure 8: Zero order plot of Atenolol 


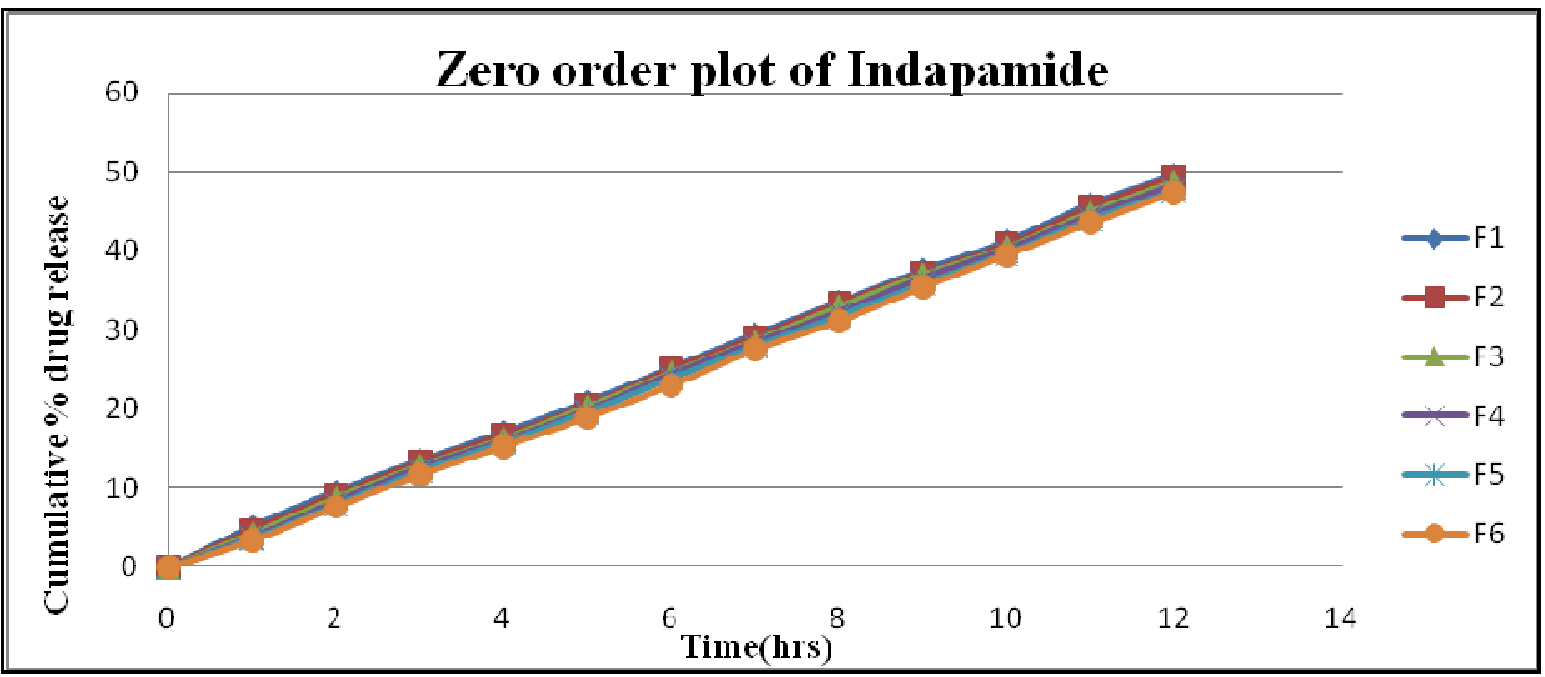

Figure 9: Zero order plot of Indapamide

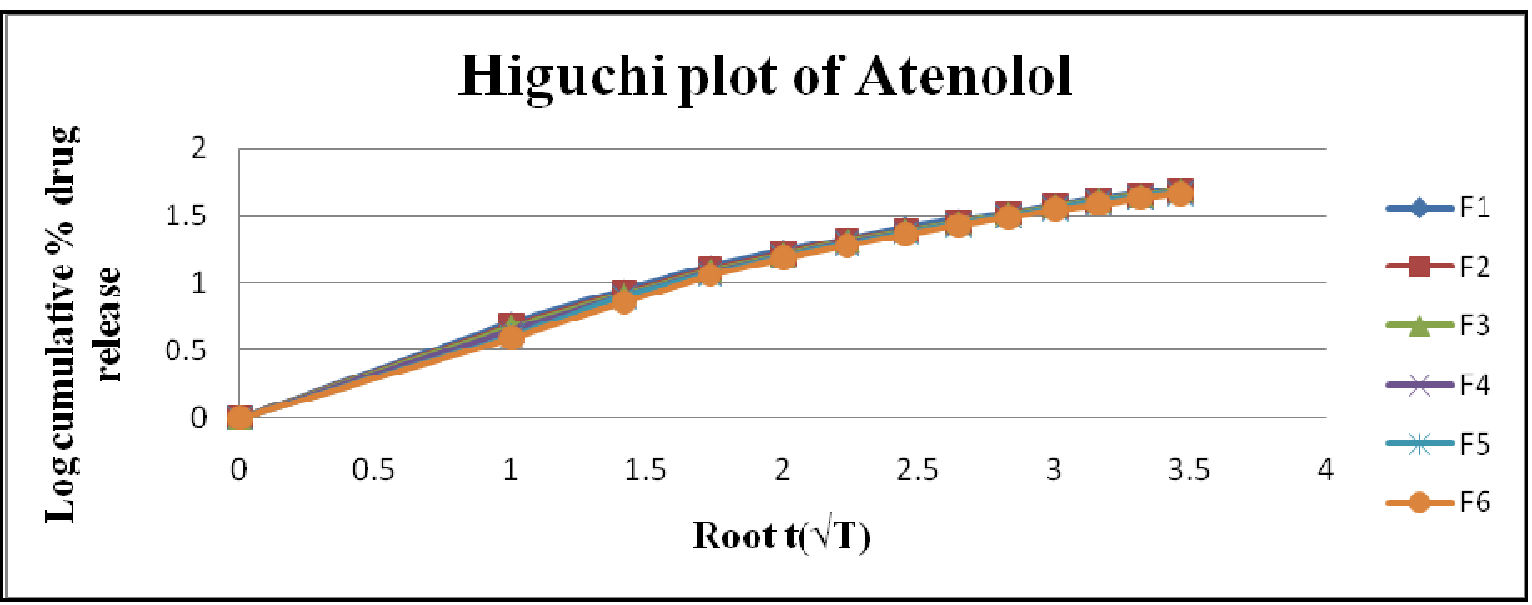

Figure 10: Higuchi plot of Atenolol

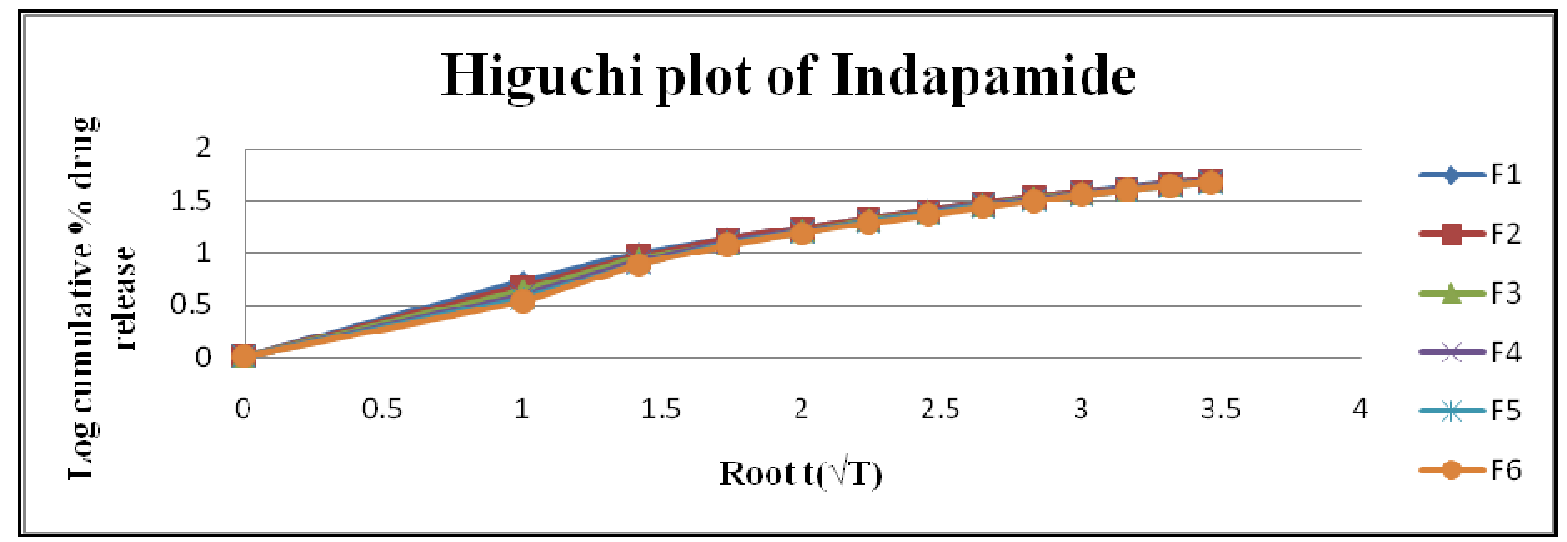

Figure 11: Higuchi plot of Indapamide 


\section{Peppas plot of Atenolol}

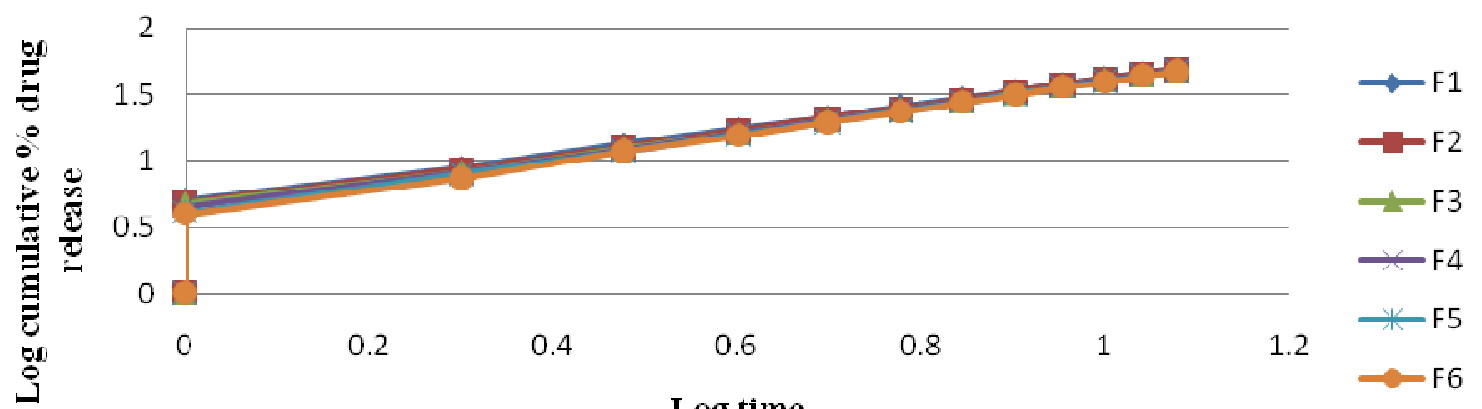

Log time

Figure 12: Peppas plot of Atenolol

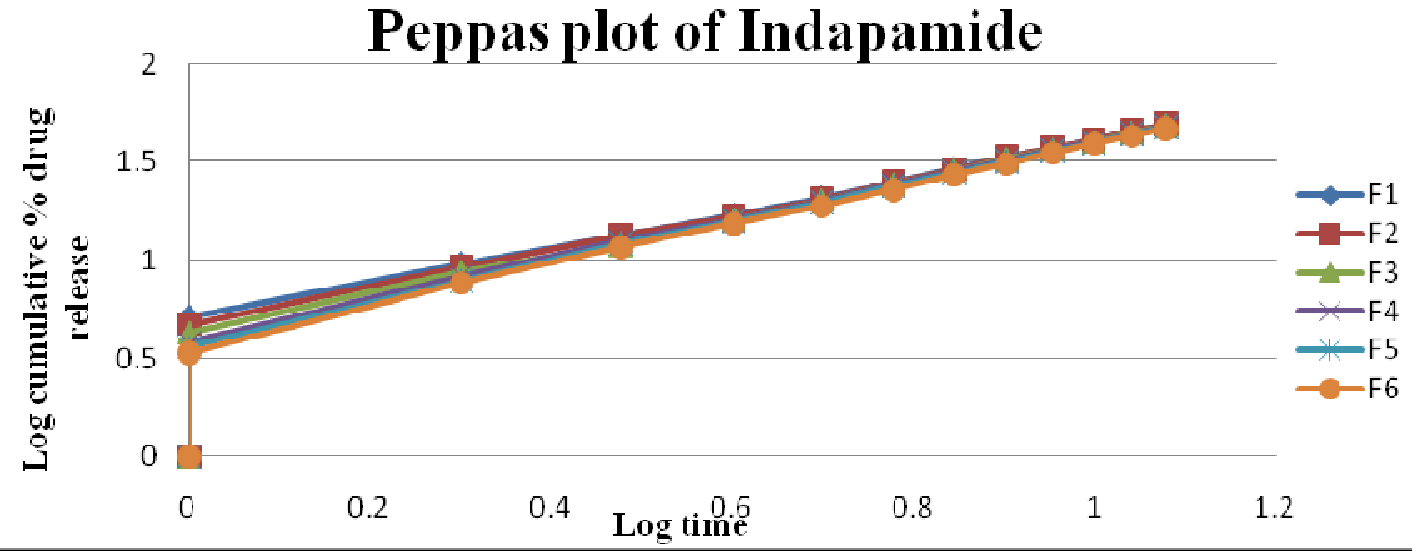

Figure 13: Peppas plot of Indapamide

The drug release kinetics zero order, Higuchi, Peppas plot were constructed. For all the formulations zero order plots showed linearity with high regression coefficient values. According to ' $n$ ' values obtained from the Korsmayer Peppas plot, it may conclude that the drug release is by super case II transport. (Shown in table 16)

TABLE 16: Release kinetics results of formulations

\begin{tabular}{|c|c|c|c|c|c|c|c|c|}
\hline $\begin{array}{c}\text { Formula- } \\
\text { tion }\end{array}$ & \multicolumn{2}{|c|}{ Zero order } & \multicolumn{3}{c|}{ Higuchi plot } & \multicolumn{4}{c|}{ Korsmayer Peppas plot } \\
\hline & Atn & Ind & Atn & Ind & Atn & Ind & Atn & Ind \\
\hline & $\mathrm{R}^{2}$ & $\mathrm{R}^{2}$ & $\mathrm{R}^{2}$ & $\mathrm{R}^{2}$ & $\mathrm{n}$ & $\mathrm{R}^{2}$ & $\mathrm{n}$ & $\mathrm{R}^{2}$ \\
\hline F1 & 0.9995 & 0.9994 & 0.9585 & 0.9557 & 1.205 & 0.8877 & 1.1919 & 0.8794 \\
\hline F2 & 0.9997 & 0.9995 & 0.9626 & 0.9601 & 1.2089 & 0.8932 & 1.2087 & 0.8915 \\
\hline F3 & 0.9997 & 0.99997 & 0.9663 & 0.9659 & 1.2132 & 0.8982 & 1.2298 & 0.906 \\
\hline F4 & 0.9997 & 0.9998 & 0.9679 & 0.9658 & 1.222 & 0.9055 & 1.2466 & 0.9156 \\
\hline F5 & 0.9998 & 0.9999 & 0.9693 & 0.9680 & 1.2325 & 0.914 & 1.2575 & 0.9233 \\
\hline F6 & 0.9997 & 0.9997 & 0.9722 & 0.9709 & 1.241 & 0.9203 & 1.2673 & 0.9304 \\
\hline \multicolumn{78}{|c|}{ Zero order, Super case II transport } \\
\hline
\end{tabular}




\section{Conclusion}

The study was undertaken with the aim to formulate and evaluate combination therapy of Atenolol and Indapamide SR matrix tablet for treatment of hypertension using delay release agent (DCP), disintigrating agent (starch) and polymer HPMC for sustained release film coating as retarding agent.

From the above result and discussion, it is concluded that the formulation of SR matrix tablets show their slow, controlled and complete release of Atenolol and Indapamide over a period of 24 hours was obtained from SR matrix tablets of $F_{1}$ formulated and the drug was released by super case II transport.

\section{Acknowledgements}

The authors were thankful to Prof. (Dr.) Preeti Kothiyal, principal of Department of pharmaceutical science Shri Guru Ram Rai Institute of Technology and Sciences, for her valuable advice regarding the research work.

\section{References}

1. Podczeck F., Drake K.R., Neton J.M., and Harian I., The strength of bi layered tablet. Europian Journal of Pharmaceutical Sciences 2008, 1- 14.

2. Lee VHL, Controlled Drug Delivery Fundamentals and Applications: Introduction, Marcel Dekker, (2nd ed) INC, New York. 1987:29.

3. John $C$ and Morten C. The Science of Dosage Form Design, Aulton: Modified release peroral dosage forms, (2nd ed) Churchill Livingstone. 2002:290-300.

4. Banker GS and Anderson NR. The Theory and Practice of Industrial Pharmacy: Tablet, Lachman, (3rd ed) Varghese Publishing House, Bombay, 1990, 171-195, 293-303.

5. Brahmankar DM and Jaiswal SB. Biopharmaceutics and Pharmacokinetics: Pharmacokinetics, (2nd ed) Vallabh Prakashan, Delhi, 2009, 399-401, 432.

6. Pires de Abreu LR, Calafatti de Castro SA, Pedrazzoli J. Atenolol quantification in human plasma by high performance liquid cfromatography: Application to bioequivalence study. AAPS PharmSci. 5: Article 21, 2003.

7. MRC working party. Medical research council trial of treatment of hypertension in older adults. Principal results BMJ 1992; 304:405-12

8. UK Prospective Diabetes Study Group; efficacy of atenolol and captopril in reducing risk of macrovascular and microvascular complications in type 2 diabetes: UK PDS 39. BMJ 1998: 317: 713-20.

9. Dahlof B, Devereux RB, Kjeldsen SE, et al: Cardiovascular morbidity and mortality in hypertension study (LIFE): a randomized trial against atenolol. Lancet 2002: 359:995-1003

10. Sever P, Dahlof P, Poulter NR, et al: the Anglo Scandinavian Cardiac Outcomes Trial: a brief history, rational and outline protocol. J Human Hypertens 2001; 15(Suppl): S11-12. 
11. Day JL, Metcalf J, Simpson CN. Adrenergic mechanisms in control of plasma lipid concentrations. BMJ 1982; $284: 1145-8$

12. Kreeft $\mathrm{JH}$, et al. Comparative trial of indapamide and hydrochlorothiazide in essential hypertension with forearm plethysmography. / Cardiovasc Pharmacol 1984;6:622-626.

13. Lu $\mathrm{Y}$, et al. Effects of the diuretic agent indapamide on $\mathrm{Na}+$, transient outward and delayed rectifier currents in canine atrial myocytes. Circ Res 1998;83:158-166.

14. Ames RP. A comparison of blood lipid and blood pressure responses during the treatment of systemic hypertension with indapamide and with thiazides. Am J Cardid 1996;77:12B-16B.

15. USP30-NF25, The official compendium of standards. The United States Pharmacopoeial Convention, 2007.

16. Shargel L and Yu ABC, Applied Biopharmaceutics and British Pharmacopoeia, London, 3rd Edn., Prentice Hall International, New Jersey, 1993, 111-167.

17. Gennaro A.R., 'Remington: The Science and Practice of Pharmacy', vol.1, Lippincott Williams \& Wilkins, Philadelphia, $20^{\text {th }}$ ed., (1990), 700-719.

18. Banker \& Rhodes CT, " Modern pharmaceutics ”, Marcel Dekker, New York, 239-261.

19. Sinco Patrick J. "Martin's physical pharmacy and pharmaceutical sciences, fifth edition, Lippincott Williams \& wikkins, A walters Kluwer company, 2006, 400-401,428-429.

20. Higuchi T.j pharma sci. 1963; 53; 1145. 